\title{
A new experiments-based methodology to define stability threshold for any vehicle exposed to flooding
}

Eduardo Martínez-Gomariz ${ }^{a *}$, Manuel Gómez ${ }^{\mathrm{a}}$, Beniamino Russo ${ }^{\mathrm{b}}$, Slobodan Djordjevićc

${ }^{a}$ FLUMEN Research Institute, Technical University of Catalonia, Barcelona, Spain;

${ }^{b}$ Group of Hydraulic and Environmental Engineering, Technical College of La Almunia (EUPLA), University of Zaragoza, Spain; ${ }^{c}$ Centre for Water Systems, University of Exeter, United Kingdom.

*Corresponding author. Email: eduardo.martinez-gomariz@upc.edu 


\section{A new experiments-based methodology to define stability threshold for any vehicle exposed to flooding}

A vehicle exposed to flooding, after losing stability, becomes buoyant and may be washed away with potential injuries and fatalities. Such vehicles cause additional disruption to traffic that is already affected by flooding, which may lead to substantial indirect economic impact, especially in urban areas. Therefore, the analysis of the stability of vehicles exposed to flooding is important in order to make decisions to reduce damages and hazards. In this research, based on an experimental campaign that included a range of twelve car models, a new methodology to obtain the stability threshold for any real vehicle exposed to flooding is developed. A Stability Coefficient $\left(\mathrm{SC}_{\mathrm{mod}}\right)$ is derived with which the vehicles can be sorted by stability against water flows and their stability functions may be determined. The experiments were conducted with three different model scales $(1: 14,1: 18$ and 1:24) and involved analysis of both friction and buoyancy effects, which made this the most comprehensive research study to date. This methodology enables the definition of a stable area in the flow depth-velocity domain for any real vehicle. A tool is provided that decision-makers in the field of urban flood risk management can employ and after defining a design vehicle they can obtain its corresponding stability threshold.

Keywords: Damage; experimental campaign; hazard; risk; urban flood; vehicles stability

\section{Introduction}

The number of vehicles in many cities seems to be ascending. Costs associated with traffic disruption are an often overlooked indirect impact of flooding (Hammond et al. 2015). Thus, it is essential to analyse the hazard regarding vehicles exposed to flooding in urban areas. The hazard study for vehicles exposed to water flows has to be based on the determination of their stability threshold. The hazard must be understood as a part of the risk, together with the vulnerability, which may be assessed from water depth and velocity (Russo et al., 2013; Sanyal and Lu, 2006; Van Drie et al., 2013). These hydraulic variables will determine the hazard level that might affect pedestrians 
(Martínez-Gomariz et al., 2016a), vehicles and properties.

Vehicles stability will be compromised when the hydraulic variables (i.e. flow depth (y) and velocity (v)) exceed a certain threshold, similar to the stability threshold of pedestrians exposed to water flows (Abt et al., 1989; Russo et al., 2013; Xia et al., 2014; Falconer et al., 2015). However, in the case of vehicles, characteristics (e.g. weight, shape and design) will determine the level of stability. A comprehensive state of the art regarding stability criteria for flooded vehicles proposed so far was developed by Martínez-Gomariz et al. (2016b).

There are three typical modes of vehicle instability: floating, sliding and toppling; the most frequent are the first two and in most cases the instability occurs as a combination of both, floating and sliding. The vehicles instability in case of floods can generate tangible direct damages due to the physical contact of water with them, but also indirect tangible damages (like loss of production) due to traffic disruption. Moreover, after losing stability the vehicle becomes buoyant and may be washed away colliding with urban elements, with potential injuries or fatalities (intangible damage). In this context, vehicles might be considered as massive debris washed away by the flood that could generate significant economic damage and compromise pedestrian safety. The city of Santa Cruz de Tenerife (Spain) on 19th October 2014 was struck by a flood caused by $139.2 \mathrm{~mm}$ rainfall over 15 hours, which was the highest recorded precipitation in the last 70 years. The consequences of this event were tangible and intangible damage: electricity cut-off for more than 4000 users, many vehicles flooded and washed away, massive material damages in properties and urban elements, two injured pedestrians and one death.

This paper presents firstly the definition of hydrodynamic forces acting on a flooded vehicle. Then the experimental set-up is outlined, where all the stability tests 
were carried out, and the choice and adequacy of model vehicles are discussed. A comprehensive description of the experimental campaign is presented next, including the case studies, evaluation of the tyre-ground friction coefficient, determination of buoyancy, influence of the scale effects and results regarding the experimental tests of stability. In this paper, a new methodology to obtain the stability threshold for any real vehicle exposed to flooding is proposed which is validated on the basis of the results of previous authors. Moreover, a comparative study with other stability criteria is carried out. Finally, some conclusions are presented regarding the methodology proposed.

\section{Hydrodynamics forces acting on a flooded vehicle}

When a vehicle is exposed to flooding it is subjected to forces due to flow and reaction forces due to the contact with the ground. The acting flow forces are the drag force $\left(\mathrm{F}_{\mathrm{D}}\right)$ and the buoyancy force $\left(\mathrm{F}_{\mathrm{b}}\right)$, and the ground reaction forces are the normal force $\left(\mathrm{F}_{\mathrm{N}}\right)$ and the frictional force $\left(\mathrm{F}_{\mathrm{R}}\right)$ (Figure 1).

Sliding instabilities will occur when water drag force $\left(F_{D}\right)$ reaches frictional force $\left(F_{R}\right)$ produced between tyre and ground. On the other hand, a buoyancy instability (i.e. no flow velocity) will be reached when the vertical pushing force $\left(F_{v}\right)$ applied by the water is entirely due to the buoyancy force $\left(\mathrm{F}_{\mathrm{b}}\right)(1)$ and equal to gravitational force $\left(F_{g}\right)$ (due to vehicle weight).

$$
\mathrm{F}_{\mathrm{b}}=\gamma_{\mathrm{w}} \cdot \mathrm{V}_{\mathrm{w}}
$$

where $\gamma_{w}$ is the water specific weight, and $V_{w}$ is the water volume displaced by the vehicle.

Nevertheless, when it concerns to hydrodynamic conditions (i.e. flow velocity) the vertical pushing force $\left(\mathrm{F}_{\mathrm{v}}\right)$ is composed by both buoyancy $\left(\mathrm{F}_{\mathrm{b}}\right)$ and lift force $\left(\mathrm{F}_{\mathrm{L}}\right)$. 
Although, for high velocities the effect of buoyancy could be neglected, thereby considering only the effect of lift force $\left(F_{L}\right)(2)$.

$$
F_{L}=\frac{1}{2} \rho_{w} v^{2} C_{L} A
$$

where $\rho_{\mathrm{w}}$ is the water density; $\mathrm{v}$ is the water velocity; $\mathrm{C}_{\mathrm{L}}$ is the lift coefficient, and $\mathrm{A}$ is the submerged area of the projection of submerged part of vehicle perpendicular to flow direction.

Forces $\mathrm{F}_{\mathrm{v}}$ and $\mathrm{F}_{\mathrm{g}}$ can be jointly called the effective vehicle weight $\left(\mathrm{F}_{\mathrm{G}}\right)$ as was proposed in Shu et al. (2011), as follows:

$$
F_{G}=F_{g}-F_{v}
$$

where:

- $\mathrm{F}_{\mathrm{g}}=\gamma_{\mathrm{c}} \cdot \mathrm{V}_{\mathrm{c}}$ with $\gamma_{\mathrm{c}}$ : vehicle specific weight and $\mathrm{V}_{\mathrm{c}}$ : vehicle volume

- $F_{v}=F_{b}+F_{L}$ : vertical pushing force due to buoyancy $\left(\mathrm{F}_{\mathrm{b}}\right)$ and lift $\left(\mathrm{F}_{\mathrm{L}}\right)$ effects

Furthermore, the frictional force $\left(\mathrm{F}_{\mathrm{R}}\right)$ can be divided into four wheels when two axles are blocked (Figure 1), or into two wheels, when only one axle is blocked. Herein both axles will be considered blocked. In addition, the vehicles have to be considered sealed when the water depth rises. The frictional force is expressed as:

$$
F_{R}=\mu \cdot F_{N}
$$

where $\mu$ is the friction coefficient between tyre and ground; and $F_{N}$ is the normal reaction force, which is equal to effective vehicle weight $\left(\mathrm{F}_{\mathrm{G}}\right)$ as long as the vehicle is parked on a flat ground.

The force due to flow is the drag force $\left(\mathrm{F}_{\mathrm{D}}\right)$ and it may be expressed as: 


$$
F_{D}=\frac{1}{2} \rho_{w} v^{2} C_{d} A
$$

where $\rho_{\mathrm{w}}$ is the water density; $\mathrm{v}$ is the water velocity; $\mathrm{C}_{\mathrm{d}}$ is the drag coefficient, which depends on Reynolds number and the shape of vehicle; and A is the submerged area of the projection of submerged part of vehicle perpendicular to flow direction.

Evidently, the system of forces is a simplification of the real situations due to unpredictability of water when a flooding occurs. It is a time-dependent process since when the water depth raises and the vehicle specific weight $\left(\mathrm{F}_{\mathrm{G}}\right)$ varies, therefore a lower water drag force $\left(\mathrm{F}_{\mathrm{D}}\right)$ is needed in considering vehicle instability.

\section{Experimental campaign}

\subsection{Description of the experimental set-up}

The experimental tests to study the stability of vehicles exposed to water flows were carried out in the flume of the hydraulic laboratory of the Technical University of Catalonia (Spain). The horizontal flume is $20 \mathrm{~m}$ long and has a square cross section 60 by $60 \mathrm{~cm}$. A rectangular motorized weir is used to specify the downstream boundary condition when flow regime is subcritical. It is made of glass walls and Bakelite bed, with slopes ranging from $0 \%$ to $4 \%$. A pumping system, composed of two pumps able to pump $601 \cdot \mathrm{s}^{-1}$ and $90 \mathrm{l} \cdot \mathrm{s}^{-1}$ respectively and working in dry conditions, supplies the water to the flume. The water is pumped to a constant level tank from where it is partially diverted to the flume, through two motorised sluice gates, while the rest is introduced into the recirculation system, through a side weir. After the sluice gates the water is stored in another reservoir with a V-notch weir, which allows discharge measurement. The calculus of the discharge through the V-side weir flume has been carried out by the Kindsvater-Shen method (USBR, 1997), employing an effective 
discharge coefficient for partially contracted weirs:

$$
Q=1.366 \cdot h^{5 / 2}
$$

where $\mathrm{Q}$ is the discharge and $\mathrm{h}$ is the hydraulic head over the weir crest.

A local slope steel model was constructed according to the design shown in Figure 2. It has been placed in the most upstream zone of the laboratory flume and the aims of its constructions are listed below:

(1) To enable efficient setting up of various slopes (instead of modifying the slope of the entire flume)

(2) To reach steady flow quicker and save time and effort during the tests since the sluice gates control panel is close to this zone

(3) To obtain multiple combinations of discharges and slopes, hence varying water depths and velocities. In addition, it is possible to test the scale model vehicles in a flat zone

(4) To carry out tests with supercritical and subcritical flows, thus assessing the complete domain of instability points according to the results of previous studies (Figure 2)

(5) The ground of this local slope set-up is raised $15 \mathrm{~cm}$ over the flume ground. This feature allowed setting a downstream boundary condition in the local slope setup itself when a $0 \%$ slope is established (i.e. subcritical flow regime occurs). In order to set the downstream boundary condition, a manually adjustable weir was installed (Figure 2), otherwise the motorised weir placed downstream of the flume should be used.

A one-dimensional numerical model was developed in order both to define the design of the local slope physical model and to programme the experimental campaign. The ODE (i.e. ordinary differential equation) corresponding to the gradually varied flow equation was integrated on the basis of Runge-Kutta 4th order numerical method (Butcher 2000). When a $0 \%$ slope is set the subcritical flow occurs in the flat zone, thus a downstream to upstream integration is carried out with fixed downstream water depth. 
With a steep non-zero slope supercritical flow regime occurs in the flat zone, therefore an upstream to downstream integration is carried out. In supercritical conditions a sufficient length for the slope reach was assumed to reach the normal depth condition at the end of it in order to set this value as an upstream boundary condition for the flat zone. Once the physical model was constructed a calibration and validation process was carried out. A Manning roughness coefficient of $0.010 \mathrm{~m}^{-1 / 3} \cdot \mathrm{s}$ was adopted, and the adequate length of the slope model was ensured in order to reach normal depth condition. The testing section, where measurements of water depth and velocity were taken, was placed one meter from the most downstream section of the flat reach. The one-dimensional calibrated model enabled to define (prior to experiments) the combinations of discharges and slopes needed to assess the sufficient number of depthvelocity pairs, in order to cover the whole depth-velocity domain according to the results of previous studies. In addition, the location of the hydraulic jump in the flat reach was studied in order to ensure that it was sufficiently away from the testing section.

\subsection{Selection of tested models}

Since the aim of this study is to propose a general approach to assessing the stability for any vehicle exposed to flooding, a great variety of scale model vehicles were tested. Firstly, a sample of 54 different real vehicles was looked at aiming to sort them according to stability conditions. Three variables were considered in order to classify the stability level of every vehicle: ground clearance, kerb weight and vehicle plan area. Higher ground clearances and a higher vehicle weight increase the stability of any vehicle. In the first case, higher water depth is needed to reach the chassis vehicle for high ground clearance, thus buoyancy will start to take effect later. In the second case, greater water volume displaced by the vehicle is needed to become buoyant for higher 
weights. On the other hand, greater vehicles plan areas need lower water depths to reach the water volume displaced by the vehicle needed to become buoyant. According to that reasoning, a stability coefficient (SC) has been derived:

$$
S C=\frac{G C \cdot M_{C}}{P A}
$$

where GC is the ground clearance, $\mathrm{M}_{\mathrm{c}}$ is the kerb weight and PA is the plan area. Stability coefficients of the real vehicles sample ranged from $16.9 \mathrm{Kg} \cdot \mathrm{m}^{-1}$ to $65.3 \mathrm{Kg} \cdot \mathrm{m}^{-}$ 1. The model vehicles were chosen according to market availability and in order to be representative of most of the vehicles. Finally, twelve scale model vehicles were selected with stability coefficient ranging from $17.8 \mathrm{Kg} \cdot \mathrm{m}^{-1}$ up to $83.2 \mathrm{Kg} \cdot \mathrm{m}^{-1}$. The model scale ratios considered were 1:14 for ten of them and 1:18 for two of them (Table $1)$.

The proposed indicator (SC) makes sense only when the vehicles comparison is carried out among vehicles with same tyres, same maintenance status and on the same ground. The most general conditions should be taken into account, including important variable such as the friction coefficient $(\mu)$ between tyre and ground. The friction coefficient, unlike other variables in the stability coefficient, is not straightforward to obtain, but it enables the most general comparison between vehicles stability. In order to consider the friction coefficient the modified stability coefficient $\left(\mathrm{SC}_{\mathrm{mod}}\right)$ is proposed as:

$$
S C_{\text {mod }}=\frac{G C \cdot M_{C}}{P A} \cdot \mu
$$

In Table 1 the stability coefficients and the modified ones for each tested vehicle are shown. 
In order to follow the initial assumption of Froude similarity, the weight of each scale model vehicle was adjusted up in order to obtain the same density as the corresponding prototype. The interior of each scale model vehicle was filled with light foam and surface treatment was carried out in order to prevent leakage of water. In this way, the weight before and after the tests was the same and thus there was no variability in the buoyancy conditions, unlike in the studies of Oshikawa et al. (2011) and Toda et al. (2013). The four wheels for each model vehicle were locked, thus the frictional force would be distributed to all of them.

\subsection{Experiments performed}

The main aim of the experimental campaign was to determine the instability of scale model vehicles for several hydraulic conditions (i.e. water depths and velocities) in order to delineate a threshold stability function. However, some tests had to be undertaken previously for the purpose of obtaining friction coefficients of each scale model vehicle as well as the buoyancy depth for each one. Therefore, two preliminary tests were carried out first, as detailed in the next subsection. In addition, after these two, another test must be undertaken in order to determine the scale effects and to prove the adequacy of the initial assumption of Froude similarity.

\section{Friction coefficients and buoyancy tests}

The friction coefficient between tyre and ground is a fundamental parameter in this study. The value of this coefficient depends on tyre material, the ground surface and on the condition of both the tyres and the road. In that respect, a comprehensive test has been carried out to determine the friction coefficient of the tyres of the scale model vehicles and the surface of the local slope set-up. In order to consider acceptable values, they ranged between 0.25 and 0.75 according to friction coefficient studies of real 
vehicles (Gerard, 2006).

Two procedures were conducted: one using a spring balance and the other based on acceleration of an object on an inclined plane. The first test consists of applying a force manually through a spring balance. The vehicle rests on the wetted surface of the flat reach of the local slope set-up and the movement of the scale model vehicle indicates that the frictional force has been reached (Figure 3). The value indicated by the spring balance (i.e. the frictional force) divided by the scale model vehicle weight is the friction coefficient value. The second procedure involved placing the scale model vehicle over a wet surface, the same one as in the local slope set-up, and increasing the angle of the surface up to the critical angle $\left(\alpha^{*}\right)$ which triggers the movement (Figure 3). The tangent of this angle ( $\left.\tan \alpha^{*}\right)$ is the friction coefficient $(\mu)$ between tyre and ground. Because of the more accurate procedure, the results of the second test were assumed as more precise and the friction coefficients are given in Table 2. As observed in these results, the friction coefficients ranged between 0.52 and 0.62 .

In addition, all scale model vehicles were tested in order to obtain their buoyancy depths. The aim of these tests was to reach the instability of the model vehicle without considering flow velocity. In order to carry out these tests a glass box of $38.9 \mathrm{x}$ $18.9 \mathrm{~cm}^{2}$ plan area was employed (Figure 4), which was sufficient to place the largest vehicle. A small $2 \mathrm{~cm}$ diameter plastic pipe was employed to fill the box slowly with water up until no wheel was in contact with the ground, at which point the buoyancy depth $\left(h_{b}\right)$ was assumed to be reached and it was scaled up to the corresponding prototype as shown in Table 2. The difference between the water depth in the recipient, when the model vehicle is inside and when it is not, indicates the water volume displaced by the vehicle. Thus, a theoretical verification was carried out by comparing the weight of the displaced volume (i.e. considering the water density) and the weight of 
the model vehicle. The maximum error obtained (i.e. percentage difference between water volume displaced and vehicle weights) was only $4.0 \%$.

\section{Scale effects}

So far, Froude similarity has been assumed allowing scaling model results up to corresponding real-world prototype. In fact, the adequacy of this similarity may only be ascertained if the scaled results (i.e. pairs of flow depth-velocity that generated vehicle instabilities) coincide to corresponding real-world prototype. All physical models with a scale ratio $\lambda \neq 1$ will have scale effects, as long as the fluid was the same, since just one identical force ratio or non-dimensional number (e.g. Froude number) can be fixed in both (i.e. model and prototype) at a time. However, these scale effects can often be neglected and methods exist to identify if those are important or not. According to Heller (2011) a scale series method has been carried out herein, through the comparison of the instability-tests results for three different scale model vehicles, Mini Cooper, of different scale ratios $(\lambda), 1: 24,1: 18$ and 1:14 (Table 1 and Figure 5).

The larger scale ratio $(1: 14)$ acts as a reference point, as it was the prototype. In this sense, the three scale models were tested in order to delineate a threshold function based on the instability points obtained in each test. The procedure for determining an instability point was to place the model vehicle in the testing section of the local slope set-up, and after establishing a slope the flow rate was increased until it caused the movement of the scale model vehicle. The measured water depth and calculated velocity was the pair of values that defined one instability point in the water depthvelocity domain. For each established slope and discharge increment (i.e. for each combination test) the model vehicles were placed in all orientations, considering it as an instability point if the model vehicle moved in one of them. Figure 6 shows scaled up prototype representation of each instability point for the three scale ratios $(1: 24,1: 18$ 
and 1:14) of the Mini Cooper model. A fit of a $(v \cdot y)$ function was used to represent the total set of instability points for all three scaled Mini Cooper. It can be noted a proper fit with a square correlation coefficient $\left(\mathrm{R}^{2}\right)$ of 0.89 . Such adequate behaviour indicates that this reproduced phenomenon follows the Froude similarity.

\section{Stability threshold for the tested model vehicles}

After proving the adequacy of Froude similarity, all scale model vehicles can be tested and the measured hydraulic variables can be scaled up to the corresponding prototype according to the scale ratio of the tested model vehicle.

All model vehicles were tested following the same procedure as explained in the previous section. As proposed in AR\&R guideline (Shand et al., 2011), in order to offer the most standard threshold possible $(\mathrm{v} \cdot \mathrm{y})$ functions have been adjusted $\left((\mathrm{v} \cdot \mathrm{y})_{\mathrm{fit}}\right)$ to the set of instability points for each model vehicle (Figure 7). This fit was conducted through the sum minimization of the vertical distances between the instability points and the $(\mathrm{v} \cdot \mathrm{y})$ function. An additional $(\mathrm{v} \cdot \mathrm{y})_{\min }$ function has been represented by the instability point with the lowest product of depth and velocity. Pairs of curves $\left((\mathrm{v} \cdot \mathrm{y})_{\min }\right.$ and $(\mathrm{v} \cdot \mathrm{y})_{\text {fit }}$ ) are very close for all cases due to a good correlation (i.e. high $\mathrm{R}^{2}$ values) of the adjusted curve $(\mathrm{v} \cdot \mathrm{y})$ for each model vehicle. The proposed stability threshold is completed with a horizontal line from the buoyancy depth until it crosses the fitted $(\mathrm{v} \cdot \mathrm{y})$ function. According to the proposed threshold function shape, it is assumed that the instabilities for low velocities are practically due to buoyancy, as was considered by Shand et al. (2011).

\section{Methodology for obtaining the stability threshold of any real vehicle}

When all the proposed stability functions are shown on one diagram (Figure 8) it is observed that the higher the location of the stability threshold, the higher the modified 
stability coefficient. Naturally and according to the meaning of this coefficient, it means that both the safety zone and the modified stability coefficient have to increase in parallel. The scatterplot of the variables $(\mathrm{v} \cdot \mathrm{y})$ constant function and modified stability coefficient shows an adequate linear correlation between both variables (Table 3 and Figure 9) with a square of correlation coefficient $\left(\mathrm{R}^{2}\right)$ of 0.93 . This adequate correlation enables to obtain whatever $(\mathrm{v} \cdot \mathrm{y})$ threshold function for a given modified stability coefficient (7), which is obtained only with the characteristics of any real vehicle.

$$
(v \cdot y)=0.0158 \cdot S C_{\text {mod }}+0.32
$$

In order to define the stability threshold fully, theoretic buoyancy depth can be calculated by expression (8).

$$
h_{b}=\frac{M_{c}}{\rho_{w} \cdot l_{c} \cdot b_{c}}+G C
$$

where $h_{b}$ is the buoyancy depth, $M_{c}$ is the weight of the vehicle, $\rho_{w}$ is the water density, $l_{c}$ is the length of the vehicle, $b_{c}$ is the width of the vehicle and GC is the ground clearance of the vehicle.

The derivation of this equation responds to the same criterion conducted to verify the results of experimental buoyancy tests, which was demonstrated to be accurate.

On the other hand, as mentioned earlier, there is a great uncertainty in determination of friction coefficient, which must be taken into account. In that respect, two modified stability coefficients may be considered, a minimum and a maximum one according to the range of friction coefficients ( 0.25 to 0.75$)$ proposed by Gerard (2006). These two modified stability coefficients will lead to two stability thresholds (9), the upper and the lower one, delineating the uncertainty area between them (Figure 10). 
Therefore, this methodology enables to obtain a safety or stable zone in the flow depth-velocity domain, which could be as accurate as the determination of friction. If pairs of values flow depth-velocity are in the uncertainty zone, a more detailed study regarding friction coefficient should be conducted in order to take decisions.

A comprehensive validation has been carried out in order to guarantee the adequacy of the proposed method. In the studies of Xia et al. (2013) an Audi Q7 model was tested and the same scale ratio was considered. A direct comparison has been undertaken as Figure 11 shows, where both previous and current study results are overlapped in the same scatterplot. All the instability points obtained by Xia et al. (2013) are found beyond the $\left(\mathrm{v}^{\cdot} \mathrm{y}\right)_{\text {fit }}$ stability threshold, which means that the proposed stable zone is adequate. On the other hand, the herein proposed method has been applied to the other tested model vehicle in Xia et al. (2013), also shown in Figure 11. In this case, on the basis of the characteristics of the Honda Accord model, the upper and lower stability threshold have been calculated (9) as well as the theoretical buoyancy depth (8). It can be observed that all the instability points obtained for the Honda Accord model are found beyond the stable zone, and out of the uncertainty zone, which indicates the adequacy and accuracy of the proposed method.

\section{Comparative study with other stability criteria}

The main and up to date criterion regarding stability of vehicles is the one proposed in the Australian Rainfall and Runoff (AR\&R) guideline. In order to update the 1987 edition of AR\&R, this guideline was revised. This revision consists of 21 projects designed to fill knowledge gaps that have arisen since the 1987 edition. The "revision project 10: Appropriate Safety Criteria for Vehicles" (Shand et al. 2011) presented a comprehensive comparison between previous guidelines and recommendations for vehicle stability and experimental and theoretical studies. The AR\&R criterion 
guarantees the stability of three types of vehicles: small passenger, large passenger and large 4WD. A comparison of the proposed method must be conducted in order to analyse the differences between both criteria. Firstly, the overlapping of the AR\&R criterion and the minimum stability threshold (i.e. Mini Cooper model) and maximum stability threshold (i.e. Mercedes AMG) is shown in Figure 12. The lower threshold obtained for Mini Cooper model seems to offer a proper fit with "large passenger" stability threshold.

However, the development of the AR\&R criterion was conducted on the basis of friction coefficient of 0.3 which is much lower that the value of 0.53 for the tested Mini Cooper model. In this way, according to the herein proposed method and fixing a value of 0.3 for friction coefficient, it is possible to obtain the characteristics of the vehicle which the stability threshold is adapted for. Figure 13 shows the most adapted vehicles for both large passenger and large 4WD stability thresholds. In the first case, after fixing the ground clearance of 0.12 as AR\&R guide proposes for this type of vehicle, a vehicle of $4.3 \mathrm{~m}$ length, $1.3 \mathrm{~m}$ width and $1250 \mathrm{~kg}$ is obtained. In the second case, after fixing the ground clearance of 0.22 as AR\&R guide proposes for this type of vehicle, a vehicle of $4.5 \mathrm{~m}$ length, $1.7 \mathrm{~m}$ width and $2000 \mathrm{~kg}$ is obtained. In both cases the stable zone is only a bit smaller, almost negligible for the large 4WD type, according to the proposed method, because of a lower value of the theoretical value of the buoyancy depth (10). It should be noted that the stability $(\mathrm{v} \cdot \mathrm{y})$ function of $0.60 \mathrm{~m}^{2} \cdot \mathrm{s}^{-2}$ in AR\&R guideline was considered according to the stability limit for pedestrians, which attracts attention since herein that stability threshold is proposed to guarantee the stability for a $2000 \mathrm{~kg}$ vehicle. Finally, not only a vehicle can be related to its stable zone through this method but, in addition, any stable zone can be related to a vehicle with defined characteristics. 


\section{Conclusions}

No previous experimental studies included a test with more than two or three scale model vehicles; therefore, it was not possible to develop a general methodology for any real vehicle. The $A R \& R$ criterion was the best reference up to now to guarantee the stability of vehicles according to three types of vehicles. Nevertheless, the criterion proposed there is not flexible enough to consider any vehicle with different characteristics.

After a comprehensive experimental campaign, where twelve scale model vehicles were tested, a new experiments-based methodology to obtain the stability threshold for any real vehicle exposed to flooding is proposed herein. The experiments were conducted with three different geometric scales (1:14, 1:18 and 1:24) and involved analysis of both friction and buoyancy effects, which makes this the most comprehensive research study to date. This methodology enables defining a stable area in the flow depth-velocity domain with sufficient accuracy for any real vehicle. In this sense, a tool is provided which decision-makers in the field of urban flood risk management can employ, by defining a design vehicle and obtaining its corresponding stability threshold.

\section{Acknowledgments}

The corresponding author wishes to thank the Spanish Ministry of Economy and Competitiveness for the personal financial collaboration in relation to the Scholarship with reference: BES-2012-051781

\section{Funding}

This work is framed on the research project Criterios de riesgo a aplicar en el diseño de sistemas de captación ante inundaciones en medio urbano. This research project is funded by the Spanish Ministry of Economy and Competitiveness with code CGL2011- 
26958.

\section{Notation}

$A=$ submerged area of the projection of submerged part of vehicle perpendicular to flow direction $\left(\mathrm{m}^{2}\right)$

$\mathrm{b}_{\mathrm{c}}=$ vehicle width $(\mathrm{m})$

$\mathrm{C}_{\mathrm{d}}=$ drag coefficient (-)

$\mathrm{C}_{\mathrm{L}}=$ lift coefficient (-)

$\mathrm{GC}=$ ground clearance $(\mathrm{m})$

$\mathrm{F}_{\mathrm{b}}=$ buoyancy force $(\mathrm{N})$

$\mathrm{F}_{\mathrm{D}}=$ water drag force $(\mathrm{N})$

$\mathrm{F}_{\mathrm{G}}=$ effective vehicle weight $(\mathrm{N})$

$\mathrm{F}_{\mathrm{L}}=$ lift force $(\mathrm{N})$

$\mathrm{F}_{\mathrm{N}}=$ normal force $(\mathrm{N})$

$F_{R}=$ frictional force $(N)$

$\mathrm{F}_{\mathrm{V}}=$ vertical pushing force $(\mathrm{N})$

$\mathrm{h}=$ hydraulic head over the weir crest (m)

$\mathrm{h}_{\mathrm{b}}=$ buoyancy depth (m)

$1_{\mathrm{c}}=$ vehicle length $(\mathrm{m})$

$\mathrm{M}_{\mathrm{c}}=$ vehicle weight $(\mathrm{kg})$

$\mathrm{PA}=$ plan area $\left(\mathrm{m}^{2}\right)$

$\mathrm{Q}=\operatorname{discharge}\left(\mathrm{m}^{3} \mathrm{~s}^{-1}\right)$

$\mathrm{SC}=$ stability coefficient $\left(\mathrm{kgm}^{-1}\right)$

$\mathrm{SC}_{\text {mod }}=$ modified stability coefficient $\left(\mathrm{kgm}^{-1}\right)$

$\mathrm{v}=\operatorname{velocity}\left(\mathrm{ms}^{-1}\right)$

$\mathrm{y}=$ water depth $(\mathrm{m})$

$\lambda=$ scale ratio $(-)$

$\mu=$ friction coefficient (-)

$\rho_{\mathrm{m}}=$ model density $\left(\mathrm{kgm}^{-3}\right)$

$\rho_{\mathrm{p}}=$ prototype density $\left(\mathrm{kgm}^{-3}\right)$

$\rho_{\mathrm{w}}=$ water density $\left(\mathrm{kgm}^{-3}\right)$

\section{References}

Abt, S.R., Wittler R.J., Taylor A., and Love D.J., 1989. Human stability in a high flood hazard zone. AWRA Water Resources Bulletin, 25 (4), 881-890. 
Butcher, J.C., 2000. Numerical methods for ordinary differential equations in the 20th century. Journal of Computational and Applied Mathematics, 125 (1-2), 1-29.

Van Drie, R., Simon, M., and Schymitzek, I., 2013. HAZARD :- Is there a better definition? \& Impact of Not accounting for buildings! In: IPWEA Annual Conference. NSW. Australia, 13pp.

Gerard, M., 2006. Tire-road friction estimation using slip-based observers.Master Thesis. Department of Automatic Control. Lund University, Sweden.

Hammond, M.J., Chen, A.S., Djordjević, S., Butler, D., and Mark, O., 2015. Urban flood impact assessment: A state-of-the-art review. Urban Water Journal, 12 (1), 14-29.

Heller, V., 2011. Scale effects in physical hydraulic engineering models. Journal of Hydraulic Research, 49 (3), 293-306.

Martínez-Gomariz, E., Gómez, M., Russo, B. 2016a. Estabilidad de personas en flujos de agua (Stability of people exposed to waterflows) in Spanish. Ingeniería del Agua. 20 (1), 43-58.

Martínez-Gomariz, E., Gómez, M., Russo, B., Djordjević, S. 2016b. Stability criteria for flooded vehicles: a state-of-the-art review. Journal of Flood Risk Management. 10pp. (record online).

Oshikawa H., Oshima T., and Komatsu T., 2011. Study on the Risk for Vehicular Traffic in a Flood Situation (in Japanese). Advances in River Engineering. JSCE, $17,461-466$.

Russo, B., Gómez, M., and Macchione, F., 2013. Pedestrian hazard criteria for flooded urban areas. Natural Hazards, 69 (1), 251-265.

Russo, B., Velasco, M., and Suñer, D., 2013. Flood hazard assessment considering climate change impacts-Application to Barcelona case study using a $1 \mathrm{D} / 2 \mathrm{D}$ detailed coupled model. In: International Conference on Flood Resilience: Experiences in Asia and Europe. Exeter, United Kingdom, 10pp.

Sanyal, J. and Lu, X.X., 2006. GIS-based flood hazard mapping at different administrative scales: A case study in Gangetic West Bengal, India. Singapore Journal of Tropical Geography, 27 (2), 207-220.

Shand, T.D., Cox, R.J., Blacka, M.J., and Smith, G.P., 2011. Australian Rainfall and Runoff (AR\&R). Revision Project 10: Appropriate Safety Criteria for Vehicles (Report Number: P10/S2/020). 
Shu, C., Xia, J., Falconer, R.A., and Lin, B., 2011. Incipient velocity for partially submerged vehicles in floodwaters. Journal of Hydraulic Research, 49 (6), 709717.

Toda, K., Ishigaki, T., and Ozaki, T., 2013. Experiments study on floating car in flooding. In: International Conference on Flood Resilience: Experiences in Asia and Europe. Exeter, United Kingdom, 6pp.

U.S. Department of the Interior. Bureau of Reclamation (USBR), 1997. Water Measurement Manual, Chapter 7. Washington, DC, USA. 317pp.

Xia, J., Chen, Q., Falconer, R.A., Deng, S., and Guo, P., 2016. Stability criterion for people in floods for various slopes. Proceedings of the ICE - Water Management. 169, 180-189.

Xia, J., Falconer, R.A., Wang, Y., and Xiao, X., 2014. New criterion for the stability of a human body in floodwaters. Journal of Hydraulic Research, 52 (1), 93-104.

Xia, J., Falconer, R.A., Xiao, X., and Wang, Y., 2013. Criterion of vehicle stability in floodwaters based on theoretical and experimental studies. Natural Hazards, 70 (2), 1619-1630. 
Table 1. Characteristics of the tested scale model vehicles

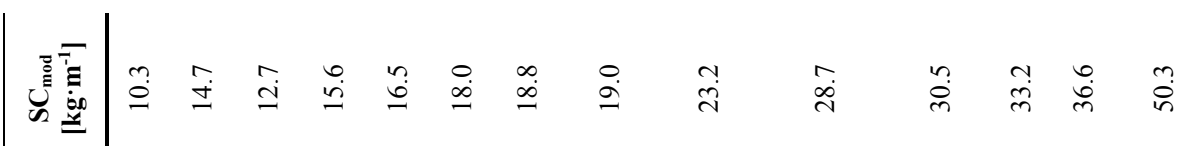

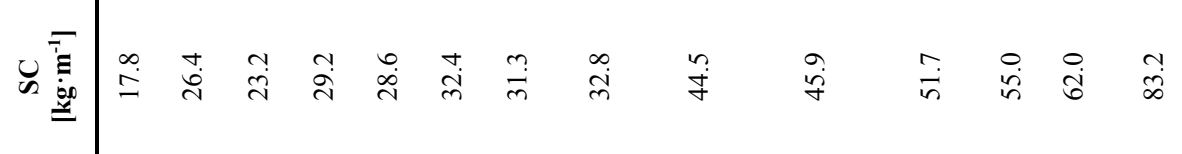

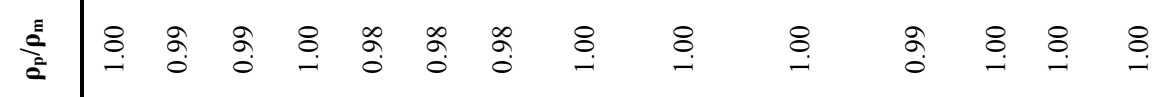

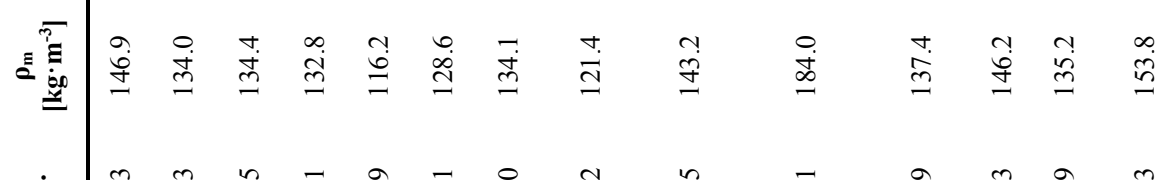

$$
\begin{aligned}
& \text { > }
\end{aligned}
$$

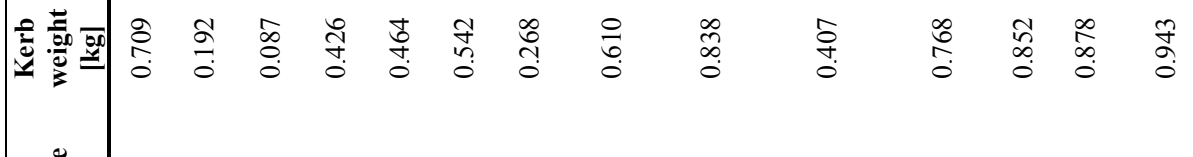

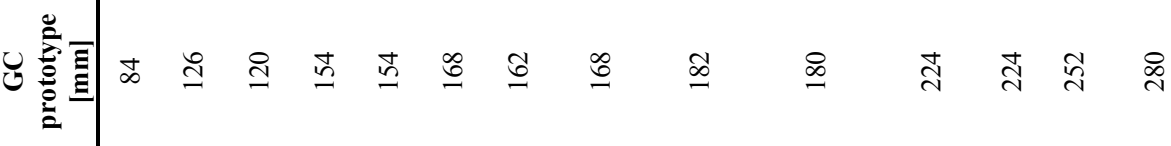

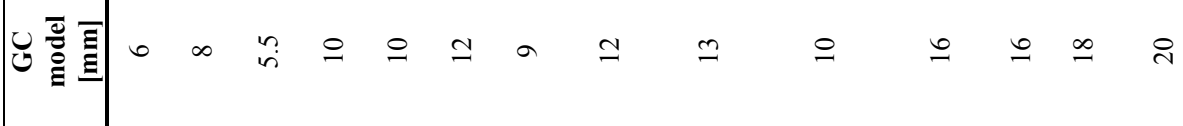

$$
\begin{aligned}
& \text { 总百胲 }
\end{aligned}
$$

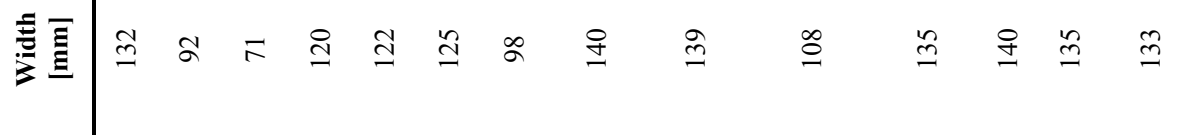

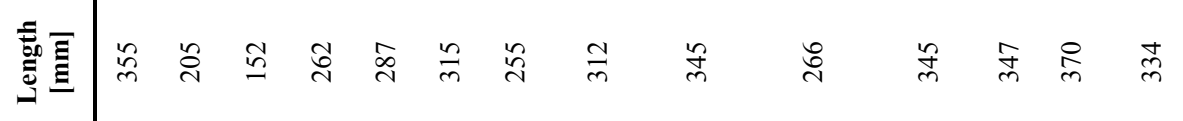

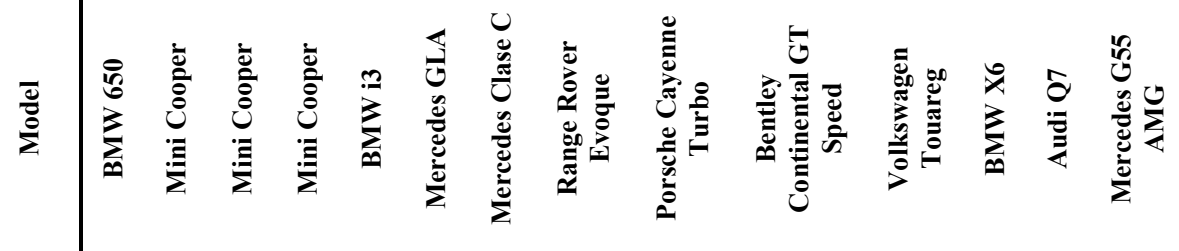

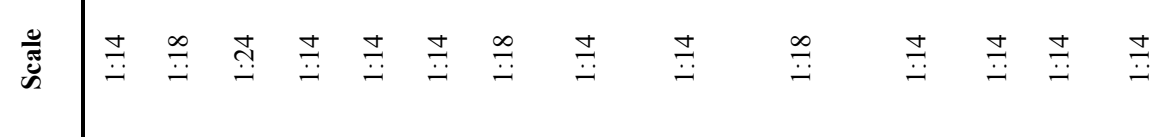

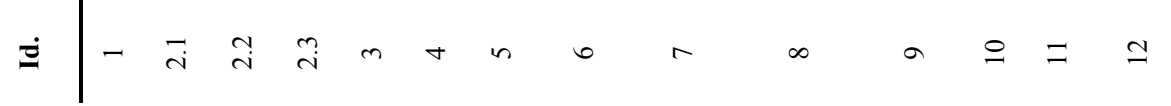


Table 2. Friction coefficients and buoyancy depths obtained experimentally for each scale model vehicle.

\begin{tabular}{lcccc}
\hline \multicolumn{1}{c}{ Vehicle } & Scale & $\boldsymbol{\mu}$ & $\begin{array}{c}\mathbf{h}_{\mathbf{b}}(\mathbf{c m}) \\
\text { (model) }\end{array}$ & $\begin{array}{c}\mathbf{h}_{\mathbf{b}}(\mathbf{c m}) \\
\text { (prototype) }\end{array}$ \\
\hline BMW 650 & $1: 14$ & 0.58 & 2.80 & 39.2 \\
Mini Cooper & $1: 18$ & 0.56 & 2.15 & 38.7 \\
Mini Cooper & $1: 24$ & 0.55 & 1.65 & 39.6 \\
Mini Cooper & $1: 14$ & 0.53 & 2.85 & 39.9 \\
BMW i3 & $1: 14$ & 0.58 & 2.90 & 40.6 \\
Mercedes GLA & $1: 14$ & 0.56 & 3.10 & 43.4 \\
Mercedes Clase C & $1: 18$ & 0.60 & 2.50 & 45.0 \\
Range Rover Evoque & $1: 14$ & 0.58 & 3.30 & 46.2 \\
Porsche Cayenne Turbo & $1: 14$ & 0.52 & 3.80 & 53.2 \\
Bentley Continental GT & $1: 18$ & 0.62 & 2.95 & 53.1 \\
Speed & & & & \\
Volkswagen Touareg & $1: 14$ & 0.59 & 3.60 & 50.4 \\
BMW X6 & $1: 14$ & 0.60 & 4.25 & 59.5 \\
Audi Q7 & $1: 14$ & 0.59 & 3.65 & 51.1 \\
Mercedes G55 AMG & $1: 14$ & 0.60 & 4.90 & 68.6 \\
\hline
\end{tabular}

Table 3. Relation of $\mathrm{SC}_{\bmod }$ and $(\mathrm{v} \cdot \mathrm{v})_{\text {fit }}$ values for each scale model vehicle

\begin{tabular}{lcc}
\hline \multicolumn{1}{c}{ Model } & $S C_{\bmod }(\mathrm{v} \cdot \mathrm{y})_{\mathrm{fit}}$ \\
\hline BMW 650 & 10.3 & 0.50 \\
Mini Cooper & 14.1 & 0.49 \\
BMW i3 & 15.0 & 0.49 \\
Mercedes GLA & 18.0 & 0.59 \\
Mercedes Clase C & 18.8 & 0.67 \\
Range Rover Evoque & 19.0 & 0.65 \\
Porsche Cayenne Turbo & 23.2 & 0.69 \\
Bentley Continental GT Speed & 23.9 & 0.87 \\
Volkswagen Touareg & 30.5 & 0.73 \\
BMW X6 & 33.2 & 0.89 \\
Audi Q7 & 36.6 & 0.89 \\
Mercedes G55 AMG & 50.3 & 1.09 \\
\hline
\end{tabular}

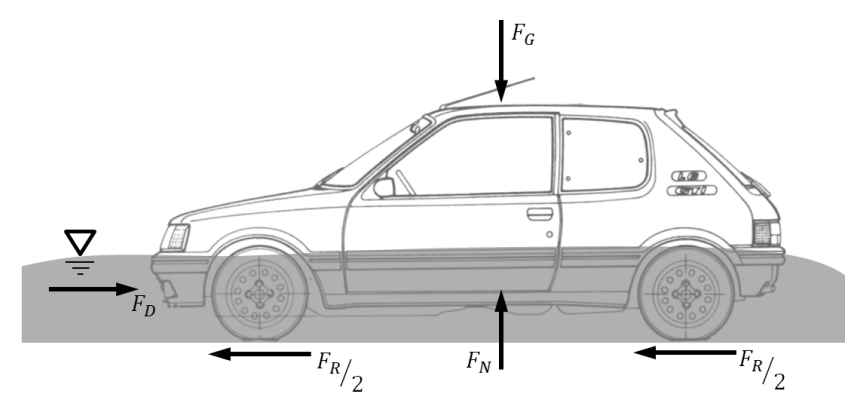

Figure 1. System of forces acting on a vehicle exposed to flooding 


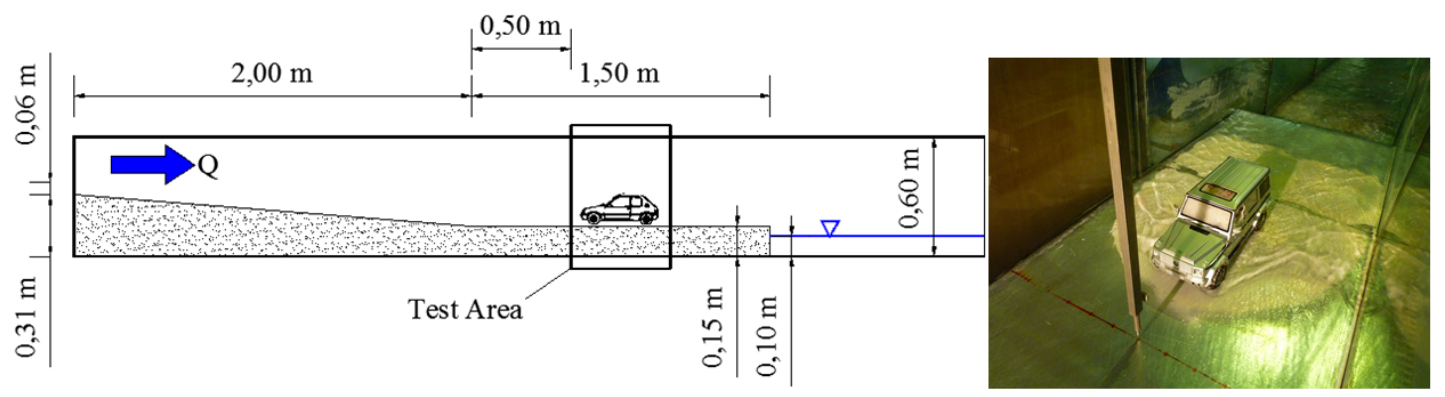

Figure 2. Local slope set-up
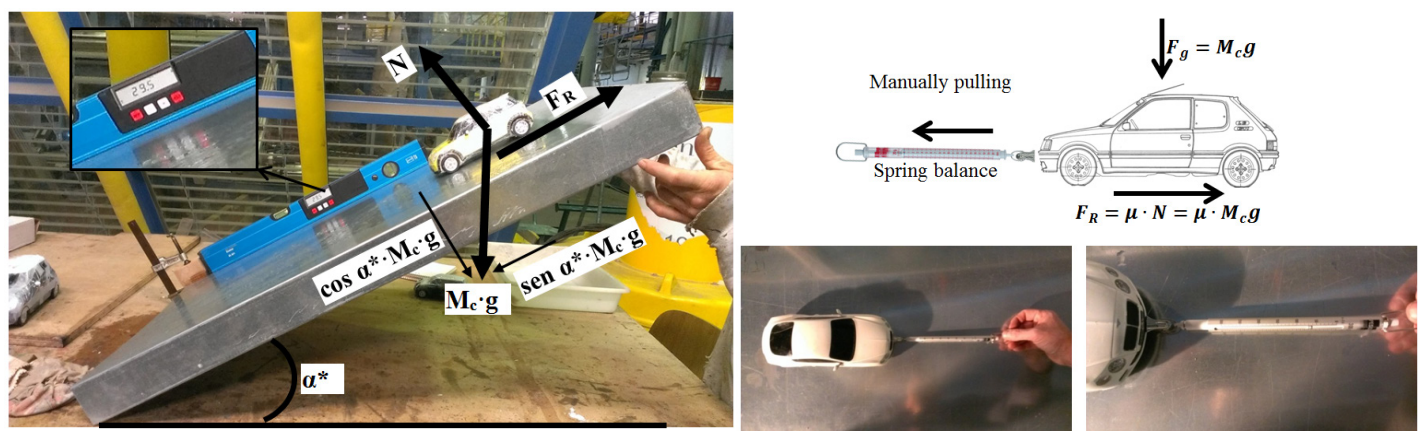

Figure 3. Friction coefficient tests
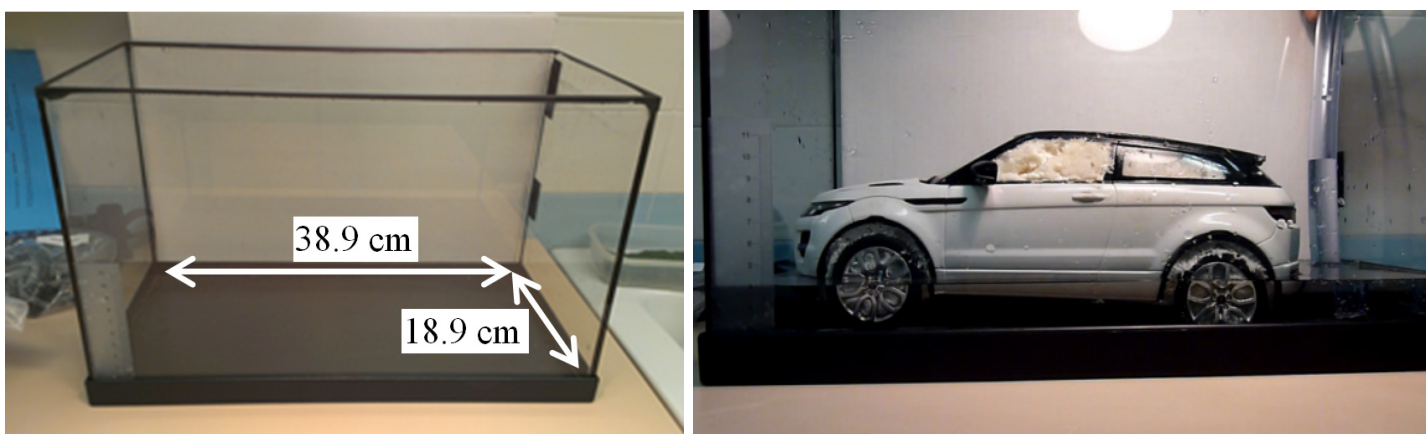

Figure 4. Buoyancy tests
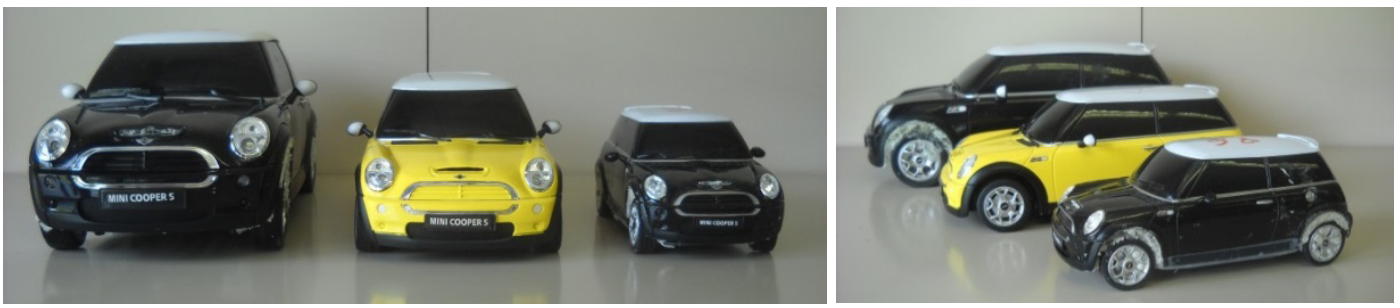

Figure 5. Three scale ratios of the same Mini Cooper model $(1: 14,1: 18,1: 24)$ 


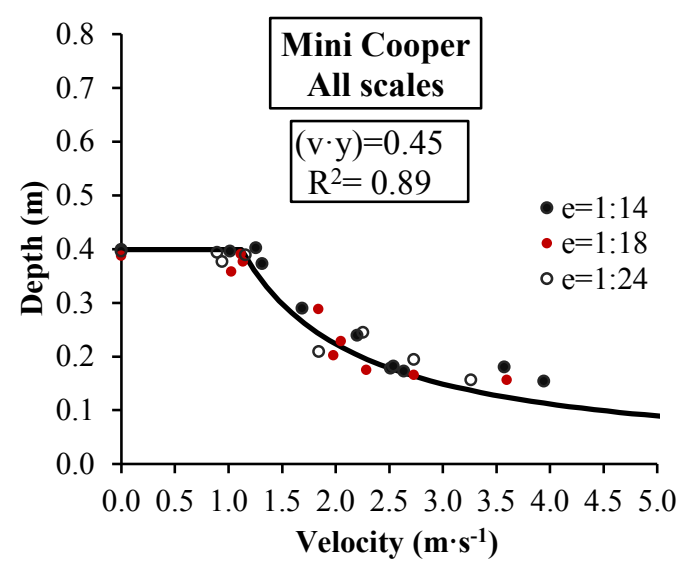

Figure 6. Instability results for the three considered scale ratios of Mini Cooper model
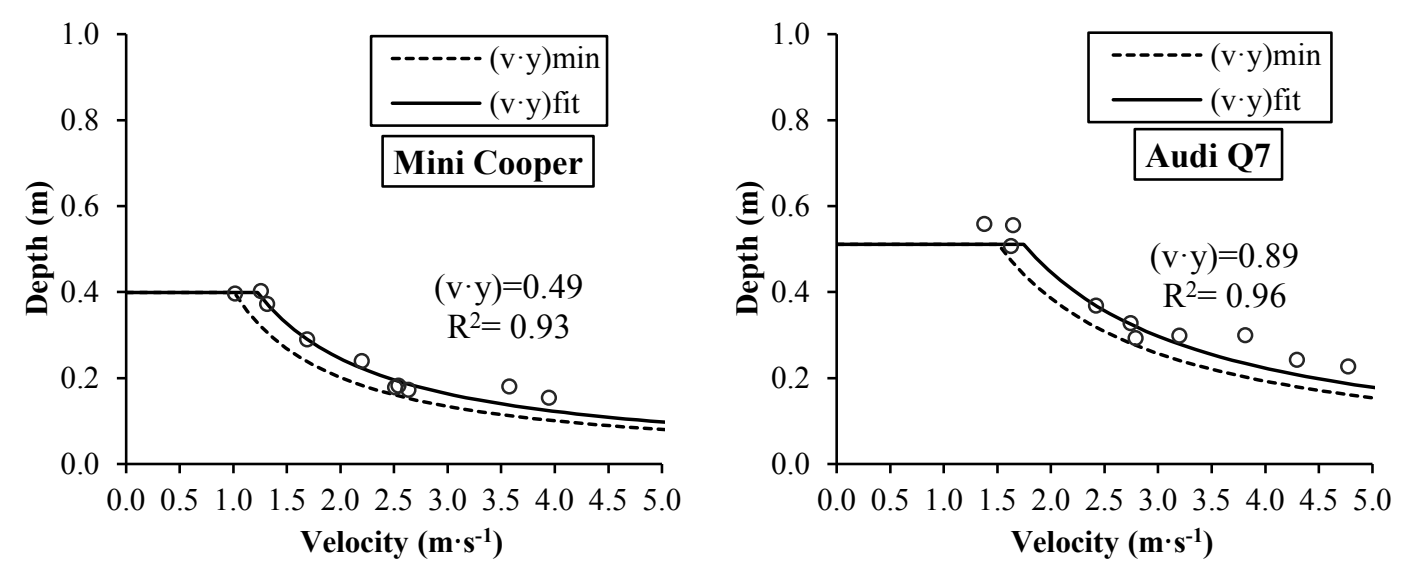

Figure 7. Instability points and proposed threshold functions for Mini Cooper and Audi Q7 models

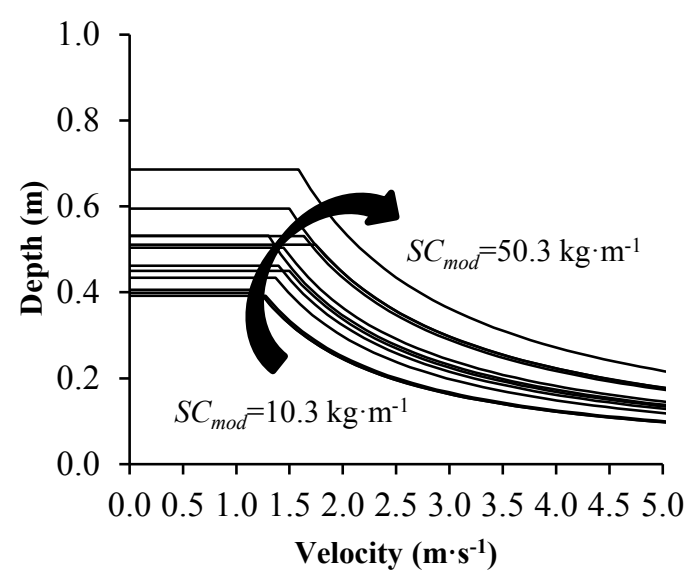

Figure 8. Overlapping of all the stability functions proposed for all the tested scale model vehicles 


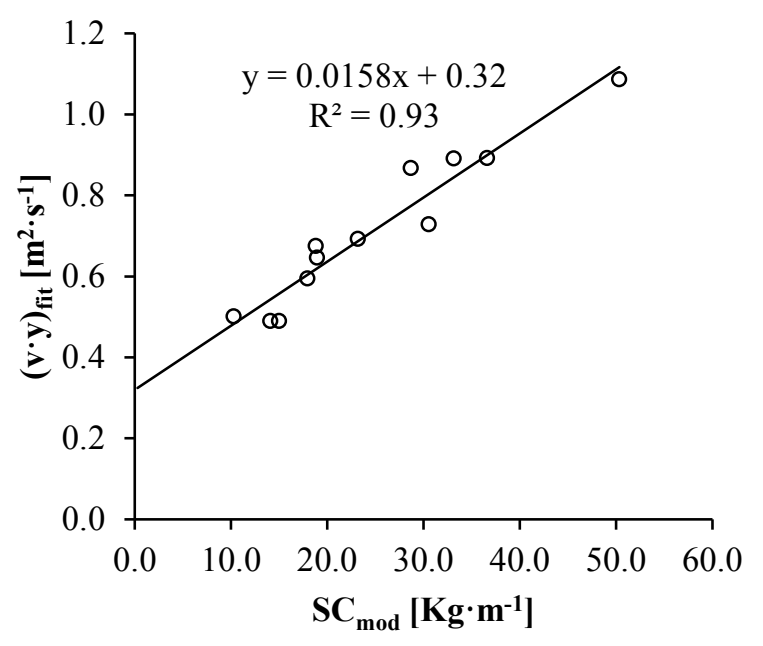

Figure 9. Scatterplot and lineal fit of $(\mathrm{v} \cdot \mathrm{y})_{\mathrm{fit}}$ and $\mathrm{SC}_{\mathrm{mod}}$ values for each tested scale model vehicle

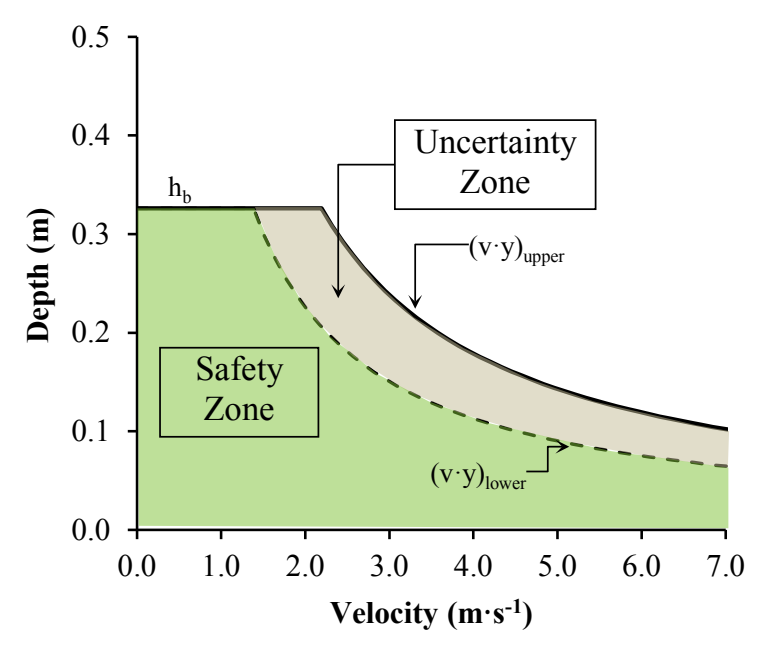

Figure 10. Definition of the proposed methodology 

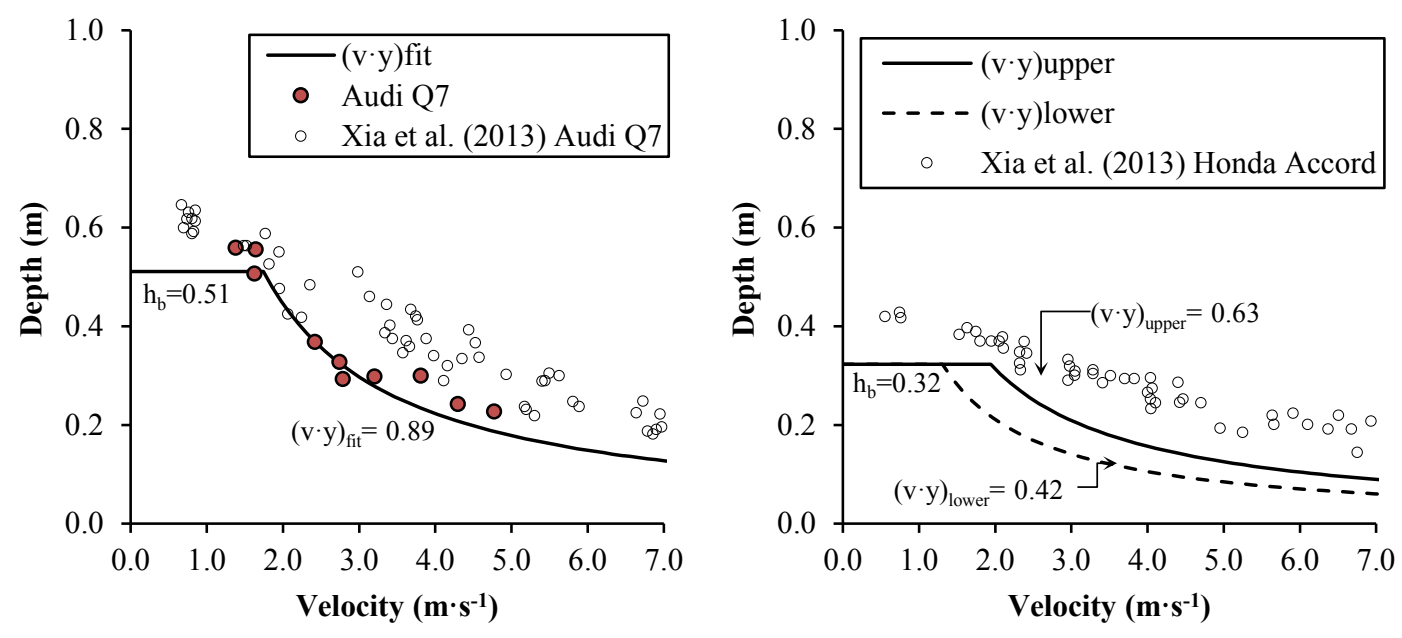

Figure 11. Validation of the proposed methodology based on Xia et al. (2013) results. Comparison between Audi Q7 model tested in the present study and in Xia et al. (2013) (left). Application of the proposed methodology herein for an Honda Accord model and comparison with the experimental results of Xia et al. (2013) for an Honda Accord model (right).

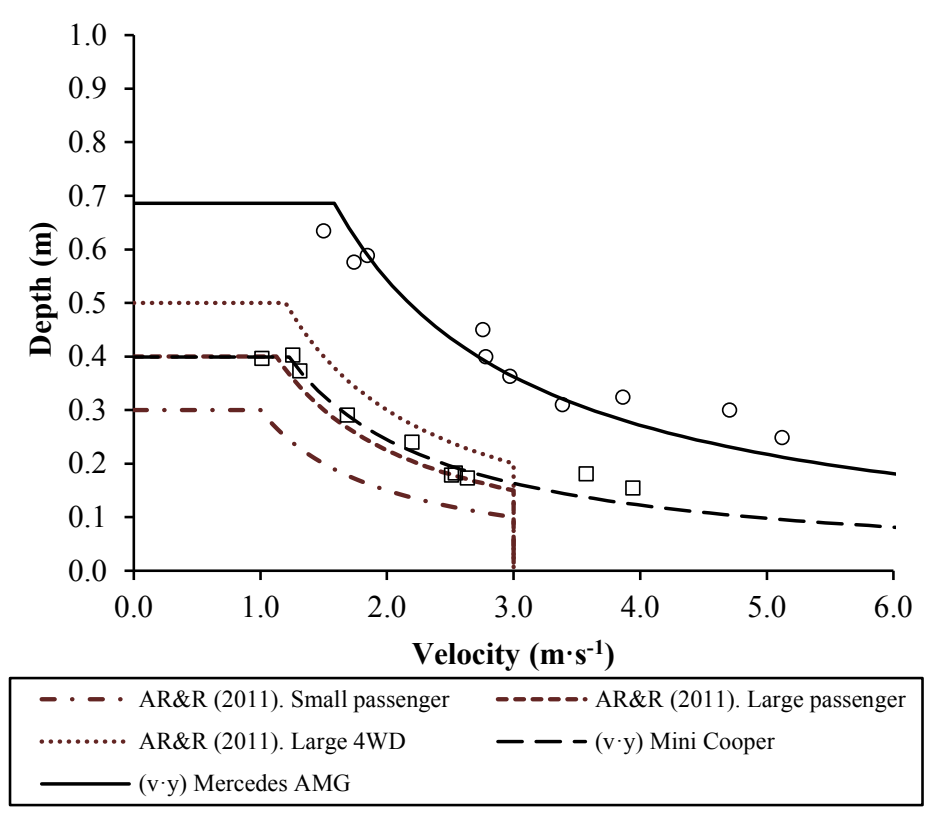

Figure 12. Comparison between the current study results and the AR\&R criterion 

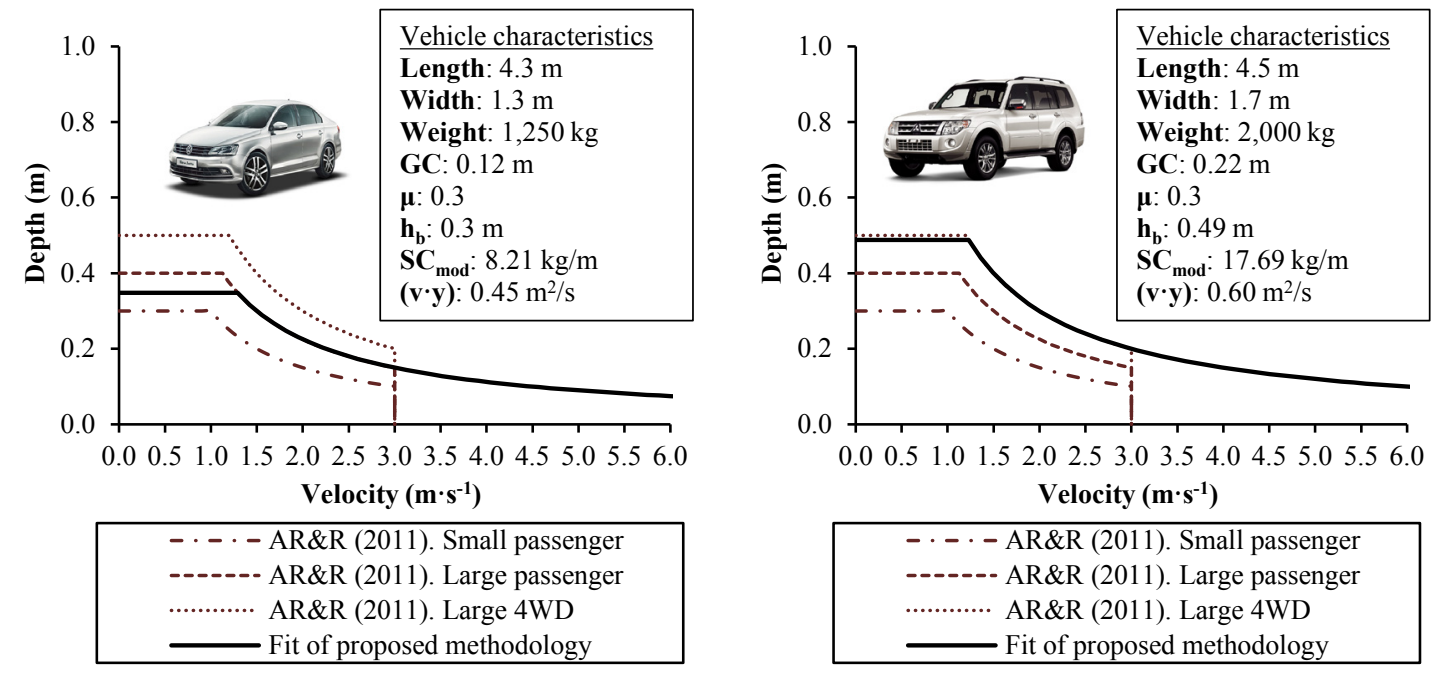

Figure 13. Application of the provided methodology to obtain the most adjustable vehicles to the AR\&R criterion 